BLS 35, No 1 2009. DOI: http://dx.doi.org/10.3765/bls.v35i1.3597

(published by the Berkeley Linguistics Society and the Linguistic Society of America)

\title{
Multi-frame Semantics, Metaphoric Extensions and Grammar
}

\author{
MYRIAM BOUVERET and EVE SWEETSER \\ Université de Rouen and University of California, Berkeley
}

\section{Introduction}

The French verbs casser, briser and rompre all translate into English most neutrally by break. And yet they are not simply tidy subcategories of the larger semantic class covered by break. We shall argue, indeed, that the oppositions between the three French verbs are shaped crucially by foregrounding or profiling of particular frames. Some of these are subsets of the BREAK frame (e.g. shattering into small bits vs. large distinguishable pieces), some partially correlated with it (e.g., non-functionality of a complex functional object correlates significantly with breaking it or some part of it), and some more orthogonal (shape of the object, possible volitionality oppositions). We argue that frame semantics needs to bring to the fore the realization that more than multiple frames are normally in play, in the semantics of a single lexical item, and the profiling of different frame oppositions may make the crucial difference in the choice between semantically close words.

It is well recognized that a wide range of lexical items and constructions evoke frames which shape the interpretation of the utterances in which they occur. Frames (Fillmore 1982, 1985, Fillmore and Atkins 1992) are structured correlations extracted from experience, often structured as dynamic scenarios with slots for participants or frame elements. Cognitively, they have a "gestalt" character: That is, evocation of any one part of the frame (e.g., the element MENU) tends to activate the rest of the frame and its elements (RESTAURANT, WAITER). It has been argued that it is frame elements (or semantic or thematic roles) which are in turn mapped onto syntactic slots in constructions. Thus, as Fillmore notes, if an agent is mentioned in a description of a BREAKing event, it will take the subject slot, while the theme will be the direct object (Sue broke the bowl); if no agent is mentioned, the theme will be the syntactic subject (The bowl broke). And, as Sullivan (2007) has pointed out most clearly, metaphoric mappings involve mapping roles in one frame onto roles in another frame. As we shall argue later, this means that the choice of a particular target domain may entail mapping different roles from the source domain frames - and different syntactic options for 


\section{Myriam Bouveret and Eve Sweetser}

expressing the metaphoric meaning of "breaking" a marriage or a silence or a secret.

Of course, not all of the frames evoked in any sentence come only from the verbs. It is well established that nouns and other lexical items evoke frames - and that constructions themselves evoke frames (Goldberg 1995, 2006). In give her a book, the major action frame is provided by the verb GIVE; in give her a kiss the major action frame is provided by the apparent direct object noun KISS; and in break one's way through the snow, the construction [X break one's way through $\mathrm{Y}$ ] provides a frame wherein the BREAK activity is interpreted as the means of creating a path or way through the snow, which is interpreted as the resisting medium. What we wish to show, however, is some of the complexity of the frame structure within the lexical semantics of the individual verbs casser, briser and rompre.

\section{Casser, briser and rompre}

English break and French casser, briser and rompre all involve the BREAK frame, as we shall call it. This is a subcase of the broader class defined by a SEPARATION frame; it involves an integral theme entity which becomes nonintegral during the event of SEPARATION, and may also involve other participant roles such as agent and instrument. SEPARATION verbs have been studied in detail, and we follow in particular the crosslinguistic work of Bowerman and colleagues (Majid, Boster, and Bowerman 2008, Bowerman 2007). The BREAK frame involves a theme which is a solid, rigid object, or a flexible object under tension. The event of BREAKing takes away the integrity of this object, which becomes more than one piece. The theme cannot be liquid or mushy, nor can it be paper or cloth (cut and tear would then apply, but not break or its French translations); and the separation cannot be achieved by use of a sharp blade as an instrument (slice, cut, etc. would then be more appropriate). Thus a soup-bowl, a mirror, a branch, a stick, a cube of ice, a loaf of bread, a chain, a wire, and a thread can all be broken in English - but a t-shirt or a handful of oatmeal or a postcard cannot.

In approaching casser, briser and rompre, we made use of the FRANTEXT (ATILF-CNRS, Nancy Université) literary corpus (1980-2007), the Le Monde 2002 corpus (search engine Le Migou, OLST Université de Montreal), various on-line newspapers including Libération, and Google. Using Google data on French presents all the expected difficulties for any on-line "world language" data: Canadian, North African and other French varieties are present (unsignaled) alongside hexagonal French; and a worldwide community of non-native users of French contribute to the French internet world. However, our other corpora are more restricted both in size and in genre, and Google allows a unique viewpoint into uncensored current usage. We are also working on a parallel project involving English verbs of BREAKing, for which the British National Corpus and UKWAC (Sketch Engine, LEXCOM) are our major sources alongside Google and on-line journalistic data. 


\section{Multi-frame Semantics, Metaphoric Extensions and Grammar}

We begin by mentioning three clear overlaps in context between casser, briser and rompre - all cases where English break might well serve as a translation.

a. Casser/briser/rompre les os 'break bones'

b. Casser/briser/rompre un fil 'break a thread/yarn/wire/string'

c. Casser/briser/rompre un mariage 'break a marriage'

We find frequent Google citations of all three verbs with the objects "bones," "thread/wire..." and "marriage"; and in some cases there is clear overlap between the actual physical circumstances described. Real physical bone-breaking done to a victim by an attacker can be expressed by all three verbs; breaking of a wire in an electronic or electrical system can also be expressed by all three verbs; we shall return to metaphoric marriage-breaking.

When we closely examine the data, however, new regularities are visible. The first 200 examples of rompre on FRANTEXT involve only four direct object NPs representing physical objects (the rest are metaphoric, like rompre le silence 'break the silence'). The four object NPs in question are un pain '(a loaf of) bread,' un croissant 'a croissant,' les os '(the) bones,' and les tendons '(the) tendons.' Neither on FRANTEXT nor on Google do we find a single example of rompre une tasse ('break a cup') or rompre une soupière ('break a soup-bowl'), although there are frequent Google instantiations of briser and casser with these object NPs. Add to this the fact that many dictionaries appear to start their entry for rompre with the examples rompre une branche ('break a branch') and rompre un bâton ('break a stick'). We also searched WSE to determine the most frequent NPs referring to physical objects, as direct objects of rompre. The top five are in order bâton 'stick,' chaine 'chain,' pain 'bread,' digue 'dike' and cou 'neck.' Searching for subjects of intransitive rompre, bâton comes in first, followed by pain and then a range of abstract nouns such as équilibre 'equilibrium,' harmonie 'harmony' and the largely abstract lien 'link.' We therefore suggest that rompre involves more specific frames than the BREAK frame; in particular, the center of the semantic category rompre involves cases where:

a. the thing broken is a long thin object and

b. the result is that there is no single whole anymore; breakage affects the whole.

Breaking a stick or a loaf of bread in half means that there is no longer $a$ stick or $a$ loaf of bread; breaking off the end would just mean there was a shorter stick or loaf.

Secondly, there is an added correlated frame where the long thin thing which is broken CONNECTS two other things, which are thus disconnected from each other by the breakage. Breaking a wire, for example, not only results in lack of integrity of the previously whole length of wire, but also could (if the wire were part of a larger system) disconnect a power source from an appliance, for exam- 


\section{Myriam Bouveret and Eve Sweetser}

ple, even though neither the appliance nor the power source is itself "broken" or damaged. Breaking a tendon disconnects the two locations in the body which were previously held together by the tendon. In this regard, it is interesting to notice the etymological link between rompre and interrompre 'interrupt.'

And finally, there seems to be a specific sub-frame associated with rompre, involving the breaking of bread. Rompre is the idiomatic way to say 'break' bread in French (expressing also contexts such as hospitality and breaking of the Eucharistic bread); it is also true that French bread loaves tend to be long and thin, so it is possible that this frame is linked to the frame involving long thin objects.

We thus have two claims on the floor. One, there are at least some cases of close synonymy between casser, briser and rompre; and two, rompre has a very different overall profile of usage from casser and briser. You would get the impression from a dictionary that rompre could refer to the breakage of a teacup but it never does, as far as we can tell.

\section{Casser/briser/rompre un fil}

Actual breakdown of the Google examples of casser/briser/rompre un fil shows both overlap and contrasts. A crucial fact here is that the French word fil translates into English variously as 'thread, yarn, wire, string, rope' - so not every scenario involving a broken fil is necessarily the same. The 6,430 Google examples of rompre un fil and rompre le fil were almost entirely divided between breakage of wires (attested predominantly on do-it-yourself repair websites and on-line user instructions for appliances), and metaphoric breakage (e.g. rompre le fil $d u$ discours 'break the thread of the conversation'). Casser brought up numerous sewing and knitting websites, with instructions as to how to deal with broken threads and yarns, alternating with some metaphoric examples, and a few cases of broken wires. And briser gave us a real mixture of broken wires, broken threads, and metaphoric cases.

Threads and wires both fit the basic BREAK frame; they're under tension. But a broken wire (as opposed to a thread broken while sewing) specifically disconnects a power source from a machine, not just one half of the wire from the other. So it is not surprising that rompre is significantly favored for broken wires. For 'break one's neck,' se rompre le cou is very common, but we also find se casser le cou (Google 10,200,000) and se briser le cou (Google 1,680,000). Again this is expected, since a neck is both a long thin connector (fitting the specific frame of rompre) and an instance of the general BREAK frame. We found no instances of rompre la cheville 'break one's ankle' but casser and briser are common in this context. Breaking the spinal cord at the neck disrupts the connection between the head and the body, not just the two halves of the spinal cord; breaking an ankle makes no such larger disruption in the system.

Casser, on the other hand, has its own individual frame associations. The most salient of these is the correlation between the BREAK frame and the frame of a complex functional object becoming non-functional when it or one of its pieces is broken. Neither briser nor rompre is tightly associated with the French 


\section{Multi-frame Semantics, Metaphoric Extensions and Grammar}

version of this RENDER NONFUNCTIONAL frame. Google gave 1,420 hits for ordinateur cassé 'broken computer,' often in contexts where it is clear that nonfunctionality is the basic problem; people are trying to diagnose a (nonvisible) problem, or to sell or give away a device to someone else who may be able to restore its functionality. Ordinateur rompu was unattested on Google, and ordinateur brisé occurred 178 times, some of which were clear references to physical smashing of computers (including videos of computer destruction). The same holds for televisions, cell phones and bicycles. Google had 1,950 examples of casser la télé 'break the television,' many of them clearly cases where the writer is wondering why the television has become nonfunctional; briser la télé turned up 8 examples, all clearly physical smashing (including statements that a particular show makes the writer so mad that he wants to briser his television). Vélo cassé 'broken bicycle' gave 1,620 hits including many inquiries as to how to get nonfunctional derailleurs back to working; but vélo brisé gave 74 results including some clear examples of physical smashing, and there were no attested examples of vélo rompu.

From this concept of complex functional physical objects becoming nonfunctional, casser is extended to abstract complex entities becoming nonfunctional. We also found instances of fichier cassé 'broken/damaged (computer) file,' and an inquiry as to whether a virus can casser un disque dur 'break/damage a hard disk' - clearly a virus could cause non-functionality but not physical breakage of the disk. And one advice-seeking user inquires Est-ce un problème de logiciel cassé, ou c'est le matériel qui s'est usé? 'Is it a problem of broken software or is it the hardware that's worn out?'

Casser also, like rompre, has a specific association with a food-breaking frame - in this case, eggs. Casser un oeuf is the normal way to say 'break an egg,' with 5,860 Google hits to 108 for briser and 1 for rompre; a number of the examples with briser appeared to involve chicks breaking shells from the inside, rather than people breaking eggs.

Briser, on the other hand, is associated with a particular sub-frame of BREAKing, which we shall call the SHATTER frame. In this frame, an object not only becomes non-integral, but is reduced to many small (perhaps indistinguishable) shards or pieces, rather than being broken in half, for example (typical with rompre). Google turned up 37,500 references for miroir brisé 'broken mirror' including many modified by en morceaux ('into pieces') or en mille morceaux ('into a thousand pieces'); crafts sites also explain how to cover objects in miroir brisé (small bits of broken mirror). Miroir cassé (certainly predicted, particularly given the loss of functionality of a broken mirror) had 9,440 hits, and miroir rompu 45. Secondly, it is noticeable that briser need not signify destruction of the whole or affect the full volume of the theme, unlike rompre. Google turns up cooking sites mentioning events such as briser l'exterieur du gâteau 'break the outside of the cake.' And things can be un peu cassé 'a little broken' (a chipped cup, for example), or un peu brisé, but no instances of objects being described as un реu rompu were found. 


\section{Myriam Bouveret and Eve Sweetser}

Notice that it is not the object per se which seems to determine the choice of a verb, but the profiled frame. In the case of un peu cassé for instance the NONINTEGRAL frame is profiled, explaining the modifier un peu (a chipped, slightly damaged cup may still be entirely functional), rather than the RENDER NONFUNCTIONAL frame present in 'ordinateur cassé.'

\section{Metaphoric Mappings}

Cognitive metaphor theory (Lakoff and Johnson 1980, 1999) argues that metaphoric linguistic usages are the linguistic manifestation of cognitive mappings between a Source domain and a Target domain. Thus, in sunny personality, the abstract target domain of personality is being construed in terms of a source domain of physical sunny-ness (as in sunny room). As Sullivan (2007) points out, we can often predict metaphoric usages, by looking closely at the source-domain usages of the relevant words; basically we need to precisely identify which frame is being mapped onto which frame. A case in point, discussed by Sullivan, is the interesting fact that one can refer to an intelligent student as a bright student or a brilliant student but not as a *sunny student; and on the other hand, a cheerful person may have a sunny disposition, or be bright and cheery, but not *brilliant and cheery. Sullivan points out that in attested literal usages about light, brilliant refers specifically to the light-emission sub-frame (e.g., a brilliant light-bulb), while bright can refer either to light-emission or ambient illumination (a bright light-bulb, a bright room), and sunny can only refer to ambient illumination (sunny room, *sunny light-bulb). It turns out that not light, but specifically the light emission frame, is what maps onto intelligence - hence bright/brilliant/ *sunny student. And ambient light level, but not light emission, maps metaphorically onto cheerfulness: hence sunny disposition, but not *brilliant disposition.

We might therefore expect that to the extent to which casser, briser and rompre are associated with different literal breaking frames, they would be mapped onto abstract domains in correspondingly different ways. And indeed we find that (1) the metaphoric uses of these three verbs show quite different profiles, and (2) some of the differences correspond predictably to mappings from the literal senses.

As a first example, a Google search for rompre un lien, casser un lien, and briser un lien ('break a link') shows 1,960 hits for rompre, 1,020 for briser, and only 241 for casser. Many of the relevant hits refer to metaphoric internet links, others to metaphoric "links" such as the connection between prices and rents. In this case, we would expect rompre to be the favorite, because a link is being primarily metaphorically understood in terms of a physical tie (rope, chain, etc.) a long thin thing which connects two other objects, and whose breaking disconnects them. The surrounding language clearly shows this, using the same valence as for a physical connector (it is entre $X$ et $Y$, 'between $\mathrm{X}$ and $\mathrm{Y}$,' for example, just like a physical link). And interestingly, the profile here is very similar to that for rompre/briser/casser un fil 'break a thread/wire,' discussed earlier, where 


\section{Multi-frame Semantics, Metaphoric Extensions and Grammar}

again rompre dominated, briser followed, and casser came in with a much smaller representation.

We should also note that metaphoric mappings may sometimes fail to map aspects of frame structure from the source domain, when they lack a counterpart in the frame of the target domain. Rompre les ponts ('break the bridges,' Google 92,400 ) is used idiomatically in French to mean 'break off a social relationship in a final way, irreversibly.' In this sense, it is quite close to synonymous with couper les ponts (literally, 'cut the bridges,' Google 691,000) - and in English, there is a corresponding idiom burn one's bridges. Now, as we have said, in literal uses, rompre and couper are largely non-overlapping: Just as with English break and cut, you can only cut with a sharp-edged instrument, while break cannot be done with such an instrument. But in the metaphoric domain of ending relationships, there is no frame role corresponding to an instrument. Thus the near synonymy of couper les ponts and rompre les ponts: In each case, assuming the relationship is construed as a bridge connecting the relevant people or social entities, physical division of the bridge maps onto disconnection between the two social entities (This 'disconnection' frame is also relevant in other "couper" meanings: Couper l'eau/l'electricité 'cut off water/electricity' couper la route à quelqu'un 'cut off someone's path'). With no mapping of instrument or manner, basically identical inferences are mapped from cutting or breaking (or for that matter, burning) onto the target domain of definitively ending a relationship. (Casser, incidentally, lacks such a metaphoric usage; all of the 1,850,000 Google uses which we have checked so far refer to literal physical bridge destruction.)

Metaphoric topic "threads" of discourse or thought or conversational interaction can also be metaphorically either cut or broken in French. Le fil est coupé and Le fil est rompu are both frequent. And note that the French verb interrompre 'interrupt' (as in La conversation est interrompue, 'the conversation has been interrupted'), actually contains rompre. A university e-mail of February 13, 2009 was headed Le dialogue est rompu avec les syndicats, 'the dialogue (of the government) with the unions is broken off' - neither casser nor briser can appropriately replace rompre here.

\section{4. "Breaking" Marriages}

We mentioned at the start that marriages are an example of something which can be (metaphorically) described as cassé, brisé, or rompu - all three verbs are possible. Does this mean that there are no differences between these different metaphoric construals? We shall show that there are such differences. But first of all, we need to be clear about the fact that a marriage (independent of its termination or breaking) can be understood metaphorically in more than one way. Naomi Quinn has argued that Americans understand marriage as (among other things) a BOND or LINK BETWEEN THE TWO PARTICIPANTS, a COMPLEX OBJECT MADE UP OF THE TWO PARTICIPANTS, and AN OBJECT OR STRUCTURE BUILT JOINTLY BY THE TWO PARTICIPANTS (Strauss and Quinn 1997, ch. 6 and 7). French speakers also seem to have these multiple 


\section{Myriam Bouveret and Eve Sweetser}

construals, among others. And different BREAK verbs would be appropriate to the different construals: For example, as discussed above, rompre would be particularly appropriate to the BOND or LINK metaphoric construal of marriage, casser or briser perhaps to the other models.

And indeed, the three ways of saying 'break a marriage' in French have quite different distributions. Rompre un mariage (Google 2,930; rompre le mariage 'break the marriage' 5,850 ) refers to legally ending a marriage, and is the primary verb used to refer specifically ending a religious marriage. This phrase is regularly accompanied by other phrases such as rompre le lien sacré 'break the sacred bond/link,' which allow us to gather that at least many of the construals of marriage involved are indeed shaped by the MARRIAGE IS A LINK/BOND metaphor.

Casser un mariage, on the other hand, is the standard usage to refer to marriage by legal divorce in civil court (Google casser un mariage 398, casser le mariage 2,510). The internet usage of this phrase is not accompanied by vivid "bond" metaphors; and we can remember that casser is the unmarked choice to refer to any complex entity becoming non-functional, which may be the most relevant issue at stake in these cases. The marriage goes from being a functioning legal entity to not being a functioning legal entity.

And finally, briser un mariage (Google 224, briser le mariage 1,080) appears to refer specifically to the action of a third party who exerts outside sexual attraction on one of the partners in the marriage, thus "breaking up" the marriage. The internet is full of examples like Jared Leto veut briser le mariage de Scarlett Johansson! (www.eparsa.fr/people/index.php?2009), 'Jared Leto wants to break up Scarlett Johansson's marriage.' Further research would be needed to know more precisely what metaphoric construals of marriage are involved here; but as with English break up, there seems no particular indication of the BOND/LINK model in these website passages - and briser, as we have seen, is focused not on long thin connecting entities, but (among other frames) on the SHATTER frame of a single entity "breaking up" into pieces which can't be reassembled.

Perhaps a more complex and puzzling abstract case is the possibility of using all three French BREAK verbs to refer to "breaking a strike." There is a clear preference for different contexts. Casser une grève clearly tends to occur with agents like the government or the army, referring to external forces of authority bringing an end to a strike. Briser une grève, on the other hand refers either to the action of outside authority or that of workers who work in violation of the strike; and rompre une grève refers primarily to the action of the union in calling off its own strike. More work would be needed to understand these uses, but it is interesting to note that with respect to both marriages and strikes, the agent of briser is an outside party, while the agents of rompre are internal to the social unit in question.

Particularly interesting metaphoric uses of French BREAK verbs are found in the idioms ils ont cassé and ils ont rompu, both meaning 'they ended a romantic or sexual relationship between them' (similar to English they broke up). Given the 


\section{Multi-frame Semantics, Metaphoric Extensions and Grammar}

metaphoric models of relationships discussed above, one would expect both of these verbs to be possible in describing metaphoric breakage of relationships. What is rather more surprising is that the syntax of these idioms is inexplicable by reference to the syntax of literal casser and rompre. Given La tasse s'est cassée and Il a cassé la tasse ('the cup broke' and 'he broke the cup'), one would expect Le mariage s'est cassé or Ils ont cassé leur mariage 'the marriage broke' or 'they broke their marriage,' and at least the latter is possible. However, one cannot say in French * L'anse et la tasse ont cassé to mean 'the handle and the cup broke (apart from each other),' using a transitive verb with a plural subject referring to the two eventually broken-apart pieces. So why is it possible to say 'they (the two romantic partners) broke' to mean that they broke apart from each other metaphorically?

The syntactic puzzle is pretty simply explained, however, by parallelism to Ils ont divorcé, 'they divorced (each other), they got divorced.' This is another case of mutual or reciprocal abstract action, ending a relationship - so it is definitely in close semantic neighborhood to the "break up" examples. The interesting point here is that only after "breaking" is being metaphorically used to talk about reciprocal relationship endings, can the "mutual" intransitive construction appropriate to divorcer be accessible to casser or rompre. ${ }^{1}$

A similar case of "attraction" into a syntactic construction via metaphoric semantic construal can be seen with the French SEPARATION verb éclater 'burst.' This is used intransitively in French (le pneu a éclaté, 'the tire burst'). This is the syntax shown predictably in metaphoric éclater de rire 'burst out laughing.' However, the reflexive form in the more recent idiom s'éclater 'have a great time, have a lot of fun' would not be predicted from literal uses of this verb. It is, however, motivated by the syntax of semantically related idioms in the metaphoric target domain of having fun. Other French idioms meaning 'have fun' include se marrer, se distraire, and s'amuser (and colloquially se bidonner, se poiler - though the very common rigoler is non-reflexive) all reflexives more literally translatable as 'enjoy oneself.' The reflexive syntactic construction is not characteristic of the literal French description of bursting events, but is very typical of French psychological predicates of amusement and indeed common over a broader range of French psychological predicates (se douter 'suspect,' $s$ 'étonner 'be surprised,' se demander 'wonder'; the reflexive construction covers "middle" semantics in French as well as core reflexive meanings). Once the verb éclater had been extended (frame-metonymically) from referring to physical laughter to referring to psychological states of amusement, those new uses were in a semantic neighborhood which made reflexive/middle syntax accessible to them.

\footnotetext{
${ }^{1}$ One might ask, why not borrow a reflexive form, used quite commonly for reciprocal actions in French, rather than a transitive form? Se séparer, 'to separate (from each other)' should in principle be a potential syntactic model here, given the semantic proximity. However, the reflexive se casser at least already has a different idiomatic meaning, namely 'leave' - in harmony with the reflexive $s$ 'en aller ('go away' - literally 'go oneself from t/here').
} 
Myriam Bouveret and Eve Sweetser

\section{Conclusions}

Casser, briser and rompre do all share association with the BREAK frame structure - but they also have characteristic associations with other quite distinct frames, such as NONFUNCTIONALITY, SHATTERING, LONG THIN OBJECTS, or DISRUPTED CONNECTION. These frames are sometimes correlated in the world with instances of the BREAK frame, and with each other, but are not necessarily correlated: Une télé brisée 'a smashed television' would necessarily be non-functional as well as in pieces, while un pain rompu 'a broken bread-loaf' may still be functional (edible) but is now non-integral and perhaps used to be long and thin. A given verb's semantics is a complex of interrelated frames - and this multiframe semantics is quite distinct for casser, briser and rompre.

Semantic frames are mapped in turn onto syntactic constructions. Therefore, as others have noted (Levin and Rappaport Hovav 2005), syntactic options shift as semantic construal shifts. Metaphoric construal of laughter as an explosion (éclater de rire) followed by frame-metonymic construal of laughter as "having fun" replaces the original explosion frame by an "having fun" frame with quite different semantic roles (Experiencer, rather than Theme). That frame in turn has its own conventional mappings onto syntax, allowing reflexive s'éclater rather than intransitive éclater, in the sense of 'have fun.'

\section{References}

Bowerman, Melissa, ed. 2007. Cognitive Linguistics 18(2). [Special issue on the semantics of cutting and breaking verbs.]

Fillmore, Charles J. 1982. Frame semantics. In Linguistic Society of Korea, ed., Linguistics in the morning calm, 111-138. Seoul: Hanshin.

Fillmore, Charles J. 1985. Frames and the semantics of understanding. Quaderni di Semantica 6(2):222-253.

Fillmore, Charles J., and Beryl T. Atkins. 1992. Towards a frame-based lexicon: The semantics of RISK and its neighbors. In Adrien Lehrer and Eva F. Kittay, eds., Frame, fields and contrasts: New essays in semantic and lexical organization, 75-103. Hillsdale, New Jersey: Lawrence Erlbaum Associates.

Goldberg, Adele E. 1995. Constructions: A construction grammar approach to argument structure. Chicago: University of Chicago Press.

Goldberg, Adele E. 2006. Constructions at work: The nature of generalization in language. Oxford: Oxford University Press.

Lakoff, George, and Mark Johnson. 1980. Metaphors we live by. Chicago: University of Chicago Press.

Lakoff, George, and Mark Johnson. 1999. Philosophy in the flesh. New York: Basic Books.

Levin, Beth, and Malka Rappaport Hovav. 2005. Argument realization. Cambridge: Cambridge University Press. 
Majid, Azifa, James S. Boster, and Melissa Bowerman. 2008. The crosslinguistic categorization of everyday events: A study of cutting and breaking. Cognition 109(2):235-250.

Strauss, Claudia, and Naomi Quinn. 1997. A cognitive theory of cultural meaning. Cambridge: Cambridge University Press.

Sullivan, Karen. 2007. Grammar in metaphor: A construction grammar account of metaphoric language. Ph.D. diss., Department of Linguistics, University of California, Berkeley.

\section{Acknowledgments}

We would like to thank colleagues in the Berkeley linguistics community and the FrameNet project, as well as participants in the BLS 35 meeting, for many helpful suggestions.

Myriam Bouveret

Département de Sciences du Langage

Université de Rouen

7 rue Thomas Becket

76118 Mont Saint Aignan

France

myriam.bouveret@univ-rouen.fr

Eve Sweetser

Department of Linguistics

1211 Dwinelle Hall

University of California, Berkeley

Berkeley, CA 94720

sweetser@berkeley.edu 